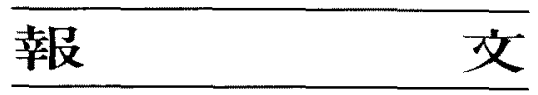

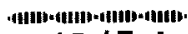

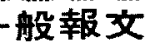

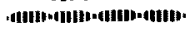

(昭和 58 年 7 月 4 日受理)

\title{
高分子膜の浸透挙動
}

\author{
名古屋工業大学工学部 木下隆利・滝沢 章・过田義治
}

\section{THE OSMOSIS THROUGH POLYMER MEMBRANE}

\section{By Takatoshi Kinoshita, Akira Takizawa and Yoshiharu Tsujita}

(Department of Polymer Engineering, Nagoya Institute of Technology, Gokiso-cho, Showa-ku, Nagoya, 466 Japan)

The osmosis through dense membrane of cellulose diacetate (CDA), cellulose triacetate (CTA) and of poly $(\gamma$-methyl L-glutamate) (PMLG) has been characterized concerning several membrane parameters, such as filtration coefficient, $L_{p}$, permeability coefficient of $\mathrm{KCl}, \omega$, and reflection coefficient, $\sigma, L_{\mathrm{p}}$ and $\omega$ of PMLG were higher than those of CTA whose equilibrium partition coefficient and degree of hydration were almost identical with those of PMLG. The differences in $L_{\mathrm{p}}$ and $\omega$ could be ascribed to the difference of diffusion mechanism of these membranes. On the other hand, reflection coefficient of these membranes, which is directly related to the membrane osmosis, was given by the following order:

$$
\mathrm{CDA} \fallingdotseq \mathrm{CTA} \gg \mathrm{PMLG} \text {. }
$$

The values of $L_{\mathrm{p}}, \omega$ and $\sigma$ in turn were related to the frictions, $f_{\mathrm{wm}}$ (water-membrane), $f_{2 \mathrm{~m}}$ (co-ion-membrane) and $f_{2 \mathrm{w}}$ (co.ion-water). The order of $\sigma$ was determined by the fact that $f_{2 \mathrm{~m}}$ of PMG- $\mathrm{KCl}$ system was considerably lower than those of cellulosic systems. This difference of $f_{2 \mathrm{~m}}$ is attributable to the fact that $\alpha$-helical PMLG has loosely packed side chain region through which the solute permeate the membrane easily, on the other hand, cellulosic membranes consisting of linear main chain have no such region.

(Received June 4, 1983)

\section{1. 緒言}

Leob扰よび Sourirajan”らにより韭刘称セルロース 膜の調製法が確立されて以来，高分子膜老用いた溶質分 離関する研究は，省土ネルギー的な分離技術の要請上 も相まってその重要性加認識されるようになり，今日も 数多くの研究 ${ }^{2}$ 加進加ら机ている。溶䨘ししてはしばし ば無機イオンが対象とされるが，この場合分離の機等は， ち密膜(ち密層)への溶質口低い溶解性亡拉散性，およひ 膜中の解離基に基つくく溶質のドナン排除効果に大別され るように思われるが，著者らは前者の機構に着目し，ち

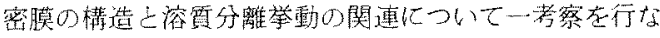
な。

膜材料ししては，溶留分離性の高いセルロース采銧状 高分子ししてセルロースジアセテートおよびれルロース トリアセテートを用い，者大安定なら世九状構造を有す るポリアミノ酸上してポリ(ケーメチルーL一グルタメート) 在用いた。膜挙動ししては，溶賈の分碓性に咸連して主

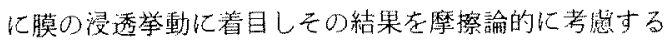
ことに上り上記銷状高狈子，ら世ん状高分子各膜の溶質 分離性の差異について基糋的な知見在得た。 


\section{2. 実験}

\section{1 試 料}

セルロースジアセテート(以下CDAと略記する), 七 ルローストリアセテート(以下CTAと略記する)は，三 菱了セテート株式会社より供与されだのでアセチル含 有量はお゙のおの $39.3 \% ， 44.1 \%$ \%ある。その皮膜はCDA， CTAともに1\%ジオキサン溶液上り室温にてガラス板を 用いてキャスト法で得，メタノ一ルにて十分溶媒置贽し た後真空乾燥して用いた。一方ポリ（ケーメチルーLーグ ルタメート)(以下PMLGと略記する)は協和醴酵工業株 式会社より提供されたもので，その你子量は粘度法 ${ }^{3)}$ に より約15万であることを確かめた。をの皮膜は，PMLG のエチレンジクロライド2\%溶液よりキャスト法で得，上 記セルロースアセテート膜と闰様の好理を行なった。膜

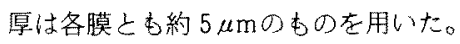

\section{2 万 法}

\section{2 .1 透水性 ${ }^{4}$}

透水性の測定には，隔膜型透過セルを用い入側に約 $1 \times 10^{-2}$ 気压の巵力を加け，出側に取り付けた半径 0.124 $\mathrm{cm}$ のキ+ピラリ一中の水のメニスカスの移動速度より 流束 $J_{\mathrm{v}}\left(\mathrm{cm}^{3} / \mathrm{cm}^{2} \cdot \mathrm{s}\right)$ を求めた。との測定より阬過係数 $L_{\mathrm{p}}\left(\mathrm{cm}^{3} / \mathrm{dyn} \cdot \mathrm{s}\right)$ が次式を用いて得られた。

$$
L_{\mathbf{p}}=\left(J_{\mathrm{v}} / \Delta p\right)_{\Delta \pi=0}
$$

ことで叻膜を介する王力差， $\Delta \pi$ は漫透压差である。

\subsection{2 イオン透過性}

透水測定上同型のセル在用い，濃度差に上り生じるイ オンの流束 $J_{\mathrm{s}}\left(\mathrm{mol} / \mathrm{cm}^{2} \cdot \mathrm{s}\right)$ をセルの出側塩濃度の経時変 化を測定して求めた。程としては $\mathrm{KCl}$ を用い高濃度側七 ル濃度 $c_{1}$ を $1.0 \times 10^{-2} \mathrm{~mol} / /$ とし，低濃度側には純水を 満たした。 $\mathrm{KCl}$ の濃度は原子吸光分光光度㖕(170-30 型，日立製作所）を用いて决定した。との測定と $\Delta \pi$ の理 諭値 $\Delta \pi_{\mathrm{cal}}$ より透過係数 $\omega(\mathrm{mol} / \mathrm{dyn} \cdot \mathrm{s})$ が次式を用いて 得られた。

$$
\omega=\left(J_{\mathrm{s}} / \Delta \pi_{\mathrm{cal}}\right)_{\mathrm{v}}=0
$$

2.2 .3 反射係数 ${ }^{6)}$

膜を介する濃度差がある状態で，との浸透仕差 $\Delta \pi か ゙$ 作用する方向之逆方向に静水生差 $\Delta p(\Delta p>\Delta \pi)$ を加的る。 この時生ずる水の流束 $J_{\mathrm{v}}$ 透水性上同じ万法で測定し， 得られた $J_{\mathrm{v}} \sim \Delta p$ の関係に拈りる $J_{\mathrm{v}}=0$ の時の $\Delta p$ の値よ り

$$
\sigma=\left(\Delta p / \Delta \pi_{\text {cal }}\right)_{J_{\mathrm{v}}=0}
$$

ここでのは反射倸数， $\Delta \pi_{\text {cal }}$ は理想溶液を仮定して求め た浸透压差であり約 $1 \times 10^{-2}$ 受压になるように調製した。

2.2.4 膜電位 ${ }^{7}$ )

各膜の有効固定電荷密度 $\phi X(\mathrm{eq} / l)$ 在求めるため膜電
位の測定を行なった。膜を張ったセルの左右の部屋にそ れぞれ濃度の異なる $\mathrm{KCl}$ 溶液 $c_{1}, c_{2}$ を満たした。濃度比 $r=c_{1} / c_{2}$ は 4 に固定した。電位差は塩橋を介した銀一塩 化銀電極用いエレクトロメータ（TR-8651 型，多 名理研工業株式会社）を用いて测定した。膜電位 $\Delta(\Delta \phi)$ と濃度 $c_{1}$ とは高濃度域にて

$$
\Delta(\Delta \phi)=\frac{R T}{F}\left(\frac{\phi X}{2 K_{ \pm}}\right)(r-1) \frac{1}{c_{1}}
$$

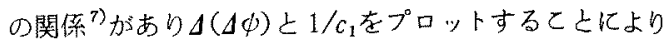
その傾きから $\phi X / K_{ \pm}$加求まる。さらに分配係数 $K_{ \pm}$を求 めることにより有効固定電荷密度 $\varnothing X$ を得た。

\subsection{5 分配係数 ${ }^{5)}$}

分配係数 $K_{ \pm}$は，

$$
K_{ \pm}=\frac{\bar{c}}{c}
$$

で定義される。とこでて，cはそれぞれ膜内扰よで溶液 中の塩濃度である。測定には約 $0.1 \mathrm{~g}$ の膜状試料を用い， $1 \mathrm{~mol} / / 0 \mathrm{KCl}$ 溶液に1 週間浸した後取り出して膜表面 を洗い，純水中にひたし塩を脱着させた。脱着平衡時の 塩濃度を原子吸光分光光度計を用いて測定し膜内濃度を 求め(5) 式を使って分配係数 $K_{ \pm}$走得た。

2.2.6 水和度 ${ }^{5)}$

約 $0.1 \mathrm{~g}$ の膜状試料を純水にひたし水が収着平衡に達 した後取り出して膜表面に付着した過稆の水を取り去っ て重量測定を行なった。との值と乾燥時の膜の重さ及び 膜の密度の值より次式を用いて水和度 $H$ を得た。

$$
H=\frac{V-V_{0}}{V_{0}}
$$

ここで $V$ は，含水膜の体栍， $V_{0}$ は膜の体皘である。な お各膜の密度はCDA $=1.032 \mathrm{~g} / \mathrm{cc} ， \mathrm{CTA}=1.302 \mathrm{~g} / \mathrm{cc}$, $\mathrm{PMLG}=1.294 \mathrm{~g} / \mathrm{cc}$ であた。

\section{3. 㥶験結果および考察}

\section{1 沪過係数，イオン透過係数と反射係数} CDA，CTA および PMLG各皮膜の透水性測定の祭に 得られる透過セル出側のキャピラリー中に扣けるメ二ス カスの移動距離 $\Delta h(\mathrm{~cm})$ 上時間の関係を図 1 に示した。 各膜よもに $\Delta h$ は時間に対し直線的に増加した。この傾 きの值と(1) 式を用いて $L_{\mathrm{p}}$ を求め婊1に結果を示した。 CTA，CDAおよびPMLGの䁲に $L_{\mathrm{p}}$ の值は増加した。 ここでCDAとCTAについて比較すると，水和度 Hの值 は表 1 より CDAが 0.17，CTAは 0.09 上異なりこの差が 主に勃いて $L_{\mathrm{p}}$ の差に反映されたのであろう。ととろが PMLGの水和度は，0.106でCTAのそれとほぼ等しい にあかかわらず $L_{\mathrm{p}}$ の値は各膜の内で最も大きい。著者 らは， $\alpha$ ーリックス構造を有するポリアミ，酸膜の低 


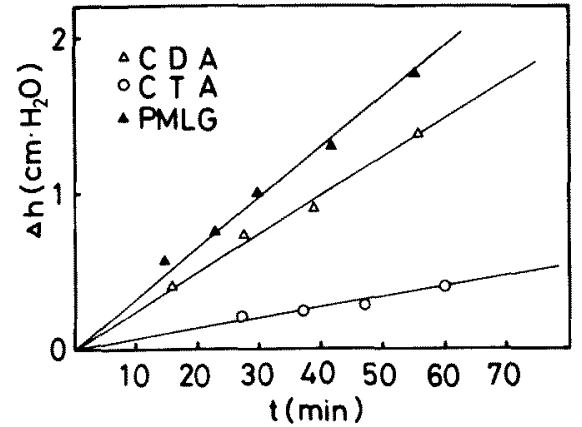

Fig. 1 Permeation curves of $\mathrm{H}_{2} \mathrm{O}$-various membrane systems at $25^{\circ} \mathrm{C}$.

CDA: cellulose diacetate, CTA: cellulose triacetate,

PMLG: $p$ oly ( $r$-methyl-L-glutameate)

Table 1 Several membrane parameters.

\begin{tabular}{cccc}
\hline & CDA & CTA & PMLG \\
\hline$H$ & 0.170 & 0.090 & 0.106 \\
$K_{ \pm}$ & 0.163 & 0.059 & 0.052 \\
$\phi X(\mathrm{eq} / \mathrm{l})$ & $3.9 \times 10^{-4}$ & $1.1 \times 10^{-4}$ & $2.6 \times 10^{-5}$ \\
$L_{\mathrm{p}}\left(\mathrm{cm}^{3} /\right.$ dyn $\left.\cdot \mathrm{s}\right)$ & $1.16 \times 10^{-10}$ & $3.19 \times 10^{-11}$ & $1.49 \times 10^{-10}$ \\
$\omega(\mathrm{mol} /$ dyn $\cdot \mathrm{s})$ & $6.65 \times 10^{-17}$ & $5.01 \times 10^{-18}$ & $1.94 \times 10^{-17}$ \\
$\sigma$ & $8.40 \times 10^{-1}$ & $7.52 \times 10^{-1}$ & $2.38 \times 10^{-1}$ \\
\hline
\end{tabular}

分子透過性は主に膜中の側銷領域を介しておこり，その 結果良好な側銷分子運動性が効いててれらポリアミノ酸 膜の透過性は比較的高いこ上を報告した ${ }^{5,7,8)}$ 。一万セル ロース系皮膜の場合は、ポリアミノ酸膜の比較的瑓な側 鎖領域に対応するような構造は存在しないであろう9。 このことから考えて表1の $L_{\mathrm{p}}$ の差は，こうしたセル口 一ス柔皮膜之ポリアミノ酸膜の構造の違いに上ると考え られる。つまりれーヘリックス構造を有するポリアミノ 酸膜の相対的な透水性の良好さは，側鎖領域を介する水 の搪散性の大きさ亿起因するあのであろう。一方 $\mathrm{KCl} の$ 透過性は，図2亿示した透過曲線(低濃度側セルの KCl 濃度 $c_{2}$ 之時間の関係) より評価される。各系において $c_{2}$ は時間之共に直線的僧加し，その傾きはCDA $>P M L G$ >CTAであった。各系の傾きの值上(2)式より透過係 数 $\omega$ を求め表 1 亿示した。この表 1 亿示されている $\mathrm{KCl}$ の分配係数 $K_{ \pm}$上水和度 $H$ の值を参照すると，分配係数 $K_{ \pm}$は $0.163(\mathrm{CDA}), 0.059$ (CTA)，0.052(PMLG)であ り概略水和度の差と相関がある。つまり溶質の溶解には 膜構造の差は特に影響しない。従って表1に掓て CDA

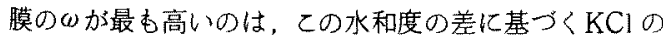
溶解性の高さによるものである。一方PMLG膜の CTA膜の値より 4 倍大きい。雨者の分配係数，水和 度の值がほほ等しいことから考えて，この心の差は， $L_{p}$

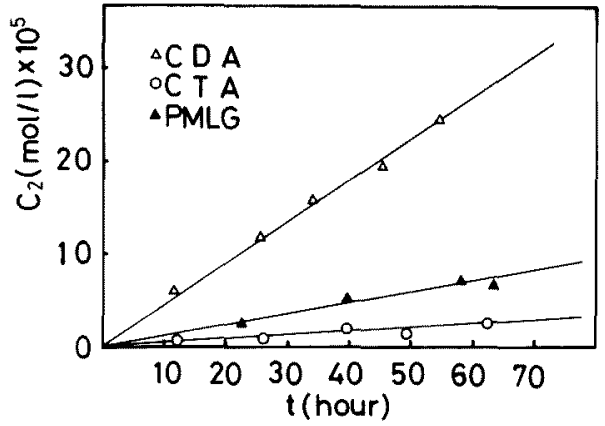

Fig. 2 Permeation curves of KCl-various membrane systems at $25^{\circ} \mathrm{C}$.

上同様而者の膜構造の差に基づく搪散性の差に起因寸る。 この様に各系の $L_{\mathrm{p}}, \omega の$ 值はポリアミノ酸上セルロース 各膜の構造のちがいに基つく溶質拡散機構の相違童裏つ けた。

溶䨘の分離性に直接関係づけられる膜パラメータは， 反射係数のである。膜を介する $\mathrm{KCl}$ の漕度差に基づく浸 透圧差に抗して種々の静水王差を加測定した $J_{v}$ と $\Delta p$ の関倸を图 3 K示した。図中の横韩の切片か $(\Delta p)_{J_{\mathrm{v}}=0}$ に刘応し，ての值を(3) 式に代入して各膜の $\sigma$ を求め表 1 K示した。CDA，CTA雨膜の $\sigma$ は約 0.8 であり理想的 な半透膜の值 $\sigma=1$ に近い值を示しているのに対しPMLG の値はかなり小さい值を示した。この結果より水和度の 低いち密膜の半透性(この場合は垍分離性) は水和度上り もむしろ膜構造の差翼に大きな影響を受けることが示唆 される。そこで各膜の浸透挙動の差をより明確にするた め3.2 K捄い上記の結果を摩擦論的 ${ }^{10)}$ 亿考察する。

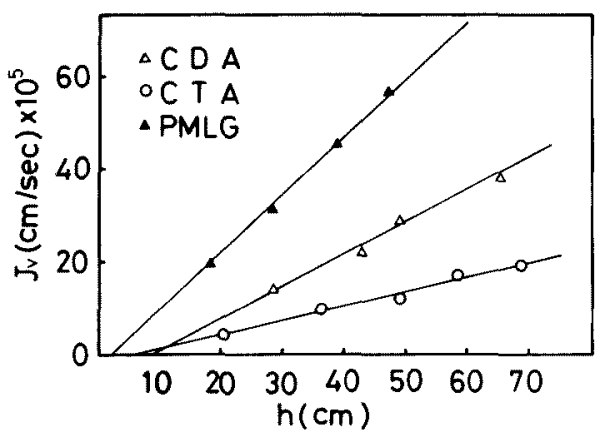

Fig. 3 The relation between $J_{\mathrm{v}}$ and applied pressure at $25^{\circ} \mathrm{C}$.

\section{2 摩擦論的解釈}

膜を介するイオンの透過性はドナン平衡理論により膜 のみかけの固定電荷密度に定量的汇律せられる7)。图 4

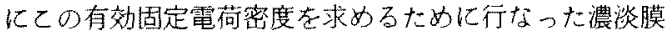
電位の測定結果を示した。各膜とも $\Delta(\Delta \psi)$ の值は低い 


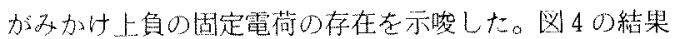

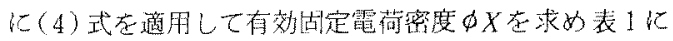
示した。と扎らち密膜の有效固定雷荷密度の值は $10^{-5}$ $10^{-4} \mathrm{eq} / l$ Łかな低く，各膜に解離性基が存在しない

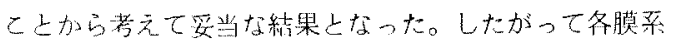

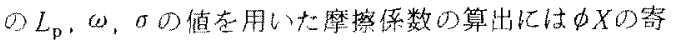
与を含まない次式がこれそれれ用いられた

$$
\begin{aligned}
& L_{\mathrm{p}}=\frac{H \bar{V}_{\mathrm{w}}}{f_{\mathrm{wm}}} \cdot \frac{1}{\Delta x} \\
& \omega=\frac{K_{ \pm}}{2\left(f_{2 \mathrm{w}}+f_{2 \mathrm{~m}}\right)} \cdot \frac{1}{\Delta x} \\
& \sigma=\frac{\omega \bar{V}_{\mathrm{s}}}{L_{\mathrm{p}}}-\frac{f_{1 \mathrm{w}}+f_{2 \mathrm{w}}}{f_{2 \mathrm{w}}+f_{2 \mathrm{~m}}} \cdot \frac{K_{ \pm}}{H}
\end{aligned}
$$

ここで $f_{\mathrm{wm}}, f_{2 \mathrm{~m}} ， f_{2 \mathrm{w}}$ はそれそれれ水一膜，副イオン一膜 および副イオンー办間の摩摖係数である。 $\bar{V}_{\mathrm{w}}, \bar{V}_{\mathrm{s}}$ はそ れぞれ水の部分モ儿体積、イホンの部分モル体皘であり， $\Delta x$ は膜厚である。乙れらの関釈式に各膜の $L_{\mathrm{p}} ， \omega ， \sigma$ の值老代入して求めた各摩摖绿数の值表 2 亿示した。 $f_{\mathrm{wm}}$ はCTA，CDA，PMLGの順に小さい值となり， CTA上CDAの比较加らセルロース采皮膜では，水和度 加高い广加水分子の摭散性屯高い事走した。さらに PMLG膜の $f_{w m}$ 吕鼠本低く, 先に述心た膜構造の差に 基つく水分子小统散性の差を裹つけた。 $f_{2 \mathrm{~m}}$ 屯 $f_{\mathrm{wm}}$ 上问 様CDA，CTAのセルロース柔皮膜では水和度の高い CDAがイオンの摭散性は亮い。またCTA\&PMLG雨 膛の比較では，水和度がほば等しいにもかかわらず，

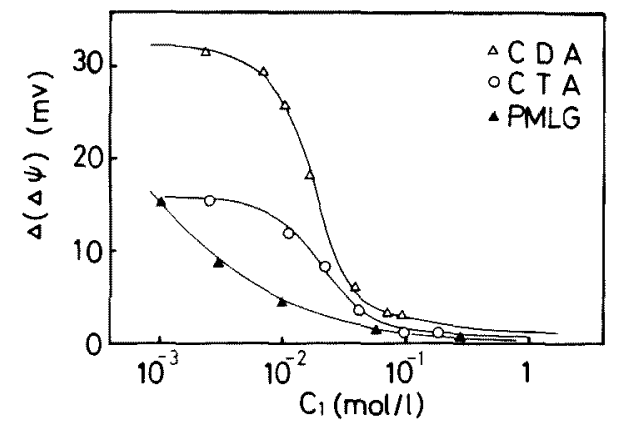

Fig. 4 Concentration dependence of membrane potential when the $\mathrm{KCl}$ concentration ratio across the membrane is fixed to 4 at $25^{\circ} \mathrm{C}$.

Table 2 Frictional coefficients $f_{\mathrm{wm}}, f_{2 \mathrm{~m}}$ and $f_{2 \mathrm{w}}$.

\begin{tabular}{cccc}
\hline$f\left(\frac{\mathrm{dyn} \cdot \mathrm{s}}{\mathrm{mol} \cdot \mathrm{cm}}\right)$ & CDA & CTA & PMLG \\
\hline$f_{\mathrm{wm}}$ & $0.53 \times 10^{14}$ & $9.50 \times 10^{14}$ & $0.26 \times 10^{14}$ \\
$f_{2 \mathrm{~m}}$ & $4.51 \times 10^{18}$ & $1.93 \times 10^{19}$ & $1.36 \times 10^{18}$ \\
$f_{2 \mathrm{w}}$ & $3.93 \times 10^{17}$ & $4.29 \times 10^{18}$ & $4.00 \times 10^{18}$ \\
\hline
\end{tabular}

PMLG膜の $f_{2 \mathrm{~m}}$ はCTAのそれより約 1 析低い值となっ た。とれらの結果より非解離性の水分子, 解離性のKC を問わずとれらの溶質と膜成分上の摩摖は膜構造に強く 依存し、ピラノース㻴を芫鎖上する銷状高分子中に书中 召溶質上膜成分との摩摖的相互作用は，ら世九状高分子 中の比較的瑓な側銷部分と溶質とのそれに比べ数倍加ら1 桁程度高いととが示された。ただし CDAとCTAの $f_{\mathrm{wm}}$ ， $f_{2 \Pi}$ の間にも大きな差異がみしめられる。てれは結晶化 度あるいは結晶構造しいった雨者の高次構造の差異に帰 せられるのであらうが，〈わしい考察は合後の問題とし て残された。一方 $f_{2 \mathrm{w}}$ の备柔の大小関係は， $f_{\mathrm{wm}}, f_{\mathrm{mm}}$ の傾问乞は異なり，水和度の最毛高いCDA膜の值加最 小值をとり水和度のほ等しいCTA，PMLG雨者の $f_{2 w}$ が隹等しい值をとったっまりイオンと獏中の水との 摩擦的相互作用は，膜の水和度に律世られると考光られ 石。ここで $f_{2 \mathrm{~m}} と f_{2 \mathrm{w}}$ の比较すなわちイオンが膜中にお いて水と膜成分のどちらと強く相互作用しているかを比 較してみるととは興味深い。表2から明らかなようにセ ルロース采皮膜中では $f_{2 m}>f_{2 w}$ であるのに対し，PMLG 膜においてはこの関係が逆になり $f_{2 \mathrm{~m}}<f_{\mathrm{zw}}$ となっている。 膜中の水含率に依存する $f_{2 \mathrm{w}}$ が CTA

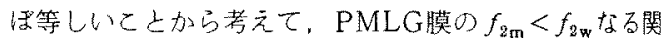
倸は，この恶の $f_{2 \mathrm{~m}}$ がセルロース采皮膜の值に比べ特に 小さい上いう事夷に起因するのではなからうか。

(7)，(8)式老用いて（9)式老書き直す之，反射係数 は次式で表わされる゙”。

$$
\begin{aligned}
\sigma & =1-\frac{K_{ \pm}}{H} \cdot \frac{1+\frac{f_{\mathrm{wm}}}{2 f_{2 \mathrm{w}}} \frac{\bar{V}_{\mathrm{w}}}{\bar{V}_{\mathrm{s}}}}{1+\frac{f_{\mathrm{zm}}}{f_{2 \mathrm{w}}}} \\
& =1-A \cdot B
\end{aligned}
$$

(11) 式の右辺のA，Bは，Z机ぞれ(10)式の $K_{ \pm} / H$ ，

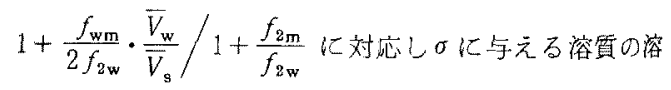
解項および拡散項とみなすととができる。したがって各

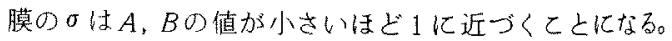
表20各摩擦係数を(10) 式に代入し，表 $10 K_{ \pm} ， H O$ 值屯用いて名膜采の $A, B$ 在求表 3 に示した。各膜の Aの值を此較するとCDA，CTA，PMLGの順に小さね 攧となり， $\mathrm{KCl}$ の溶解性のみから考えるとPMLGの。 が最む大きくなるはずである。一万Bの值は、これとは 逆にCDA，CTA，PMLGの順に大きな值をとり，結局 のとしろPMLGの 0 が他の膜に比へ小さくなるという 慗実は，拡散項に起因していることが明らがなる。る こで (10) 式の拡敬項に注目する。(10) 式拡散項分子の 摩摖係数の比 $f_{\mathrm{wm}} / f_{2 \mathrm{w}}$ は表 3より条采しb $10^{-4} \sim 10^{-6}$ で 
Table 3 The effective factors which determine the values of $\sigma$.

\begin{tabular}{cccc}
\hline & CDA & CTA & PMLG \\
\hline$\sigma$ & $8.40 \times 10^{-1}$ & $7.52 \times 10^{-1}$ & $238 \times 10^{-1}$ \\
$A$ & 0.96 & 0.66 & 0.49 \\
$B$ & 0.08 & 0.18 & 0.75 \\
$f_{\mathrm{wm}} / f_{2 \mathrm{w}}$ & $1.35 \times 10^{-4}$ & $2.22 \times 10^{-4}$ & $6.50 \times 10^{-6}$ \\
$f_{2 \mathrm{~m}} / f_{2 \mathrm{w}}$ & 11.5 & 4.50 & 0.34 \\
\hline
\end{tabular}

あり1に比へ無視し得るためにBに与える影響は小さい。 それに対し分母の $f_{2 \mathrm{~m}} / f_{\mathrm{2w}}$ の值は，此較的大きいため拡 散項Bはこのイオンと膜求よびイオンと水上の摩擦係数 の比によて決定されると言えよう。すなおちCDA， CTA膜采ののがに近い值をとるのは，乙れらの膜の $f_{2 \mathrm{~m}} / f_{2 \mathrm{w}}$ 力s PMLGOそれより 1 析以上大きく，てれに 起因して搪散項Bが小さくなるためであることがわかる。 さらに先にも述べたように $f_{2 \mathrm{w}}$ が膜構诰に依存せず膜の 水含率のみに依存するあの上すれば，七ルロース采皮膜 ŁPMLG膜ののの差すなわら半透性の差は，膜構造の 差異に基つくく $f_{2 \mathrm{~m}}$ の差に起因するとの結論が得られる。

\section{4. 結 論}

解離性の低いち密膜 CDA，CTA，PMLGの反射係数 のは(10)，(11）式に示される上うに溶貫の溶解性と拉散 性に律せられるが，特に桩散性の寄与が大である。るし てCDA，CTA膜采ののが，PMLGのを扎より高く理想 的な半透膜の值に近いのは，膜成分上溶賈 $(\mathrm{KCl}) \longleftarrow 0$ 摩 嚓的相互作用が，前者の力が後者に比べ数倍から1桁程 度大であるという事実に帰せられた。これは，ピラノー 又環老主銷とする鎖状畄分子であるCDA，CTA膜中に， PMLG膜中の分子運動性の高い比較的玶な側銧領域に 対応する構造が存在しないためであるう。

付記：本研究の奏験在進めるにあたり御協力下さった 名古屋工業大学辻井彰司，浅野克己雨氏には心加感謝 します。また本研究の概要は，繶維学会昭和 58 年度年
次大会(東尔)で発表しました。なお，本研究は科学研究 費補助金一般研究（B）No.574900120瑷助在得遂行心た しました。

$$
\text { 文献 }
$$

1) S. Leob and S. Sourirajan, Advances in Chem. Ser., No. 38, 117 (1963).

2) P. Meares Ed., "Membrane Separation Processes", Elsevier, New York (1976).

H. Strathmann, J. Membr. Sci., 9, 121(1981). H. K. Lonsdale, J. Membr. Sci., 10, 81 (1982).

3) P. Doty, J. Am. Chem. Soc., 78, 947 (1956).

4) A. Gliozzi, R. Morchio and A. Ciferri, J. Phys. Chem., 73, 3063 (1969).

5) T. Kinoshita, S. Hayashi, A. Takizawa and Y. 'Tsujita, J. Macromol. Sci. Phys., B17, 39 (1980).

6) A. Gliozzi, V. Vittoria and A. Cifferri, $J$. Membr. Sci., 8, 149 (1972).

7) T. Kinoshita, T. Yamashita, T. Iwata, A. Takizawa and Y. Tsujita, J. Macromol. Sci. Phys., B22, 1 (1983).

8) A. Takizawa, T. Hamada, H. Okada, S. Imai and S. Kadota, Polymer, 15, 157 (1974).

A. Takizawa, T. Hamada, H. Okada, S. Kadota and H. Nonoyama, J. Appl. Polymer Sci, 18 , 1443 (1974).

A. Takizawa, T. Taniguchi, I. Yamamuro and Y. Tsujita, J. Macromol. Sci. Phys., B13, 203 (1977).

T. Kinoshita, N. Okazaki, A. Takizawa and Y. Tsujita, Polymer, 20, 791 (1979).

9) H. Strathmann and P. Scheible, Kolloid-Z., 230, 341 (1969).

10) O. Kedem and A. Katchalsky, Biochim. Biophys. Acta., 27, 229 (1958); J. Gen. Physiol., 45, 143 (1961).

11) K.S. Spiegler and O. Kedem, Desalination, 1, 311 (1966). 